\title{
La investigación: una poderosa herramienta del proceso de enseñanza-aprendizaje ${ }^{1}$
}

\section{Renata Rodrigues*}

El Congreso Interdisciplinario de Investigación es un congreso anual concebido, hace seis años, como un espacio privilegiado para que investigadores de todas las áreas y unidades académicas de la Universidad pudiesen compartir las investigaciones que están realizando. Con él nos propusimos fortalecer la difusión de nuestro quehacer investigativo a nivel interno de la Universidad.

Muchos de nosotros, en diferentes momentos, hemos demandado mayor información sobre las investigaciones que estamos realizando. Muchas de ellas las podemos leer en los medios de difusión científica que tenemos en la Universidad, como la revista Encuentro, los Cuadernos de Investigación, la Revista de Derecho, los Cuadernos de Investigación de Nitlapan, o la Revista de Historia, del INHCA. Sin embargo, mucho de lo que investigamos es publicado en otros medios o, en algunos casos, no es publicado, lo que impide que tengamos acceso a su contenido. El medio de difusión privilegiado de las investigaciones científicas son los medios impresos o digitales, pero es en espacios como este que podemos compartir entre investigadores, dialogar sobre las dificultades que hemos enfrentado al realizar una investigación, los motivos por los cuales trabajamos con una metodología u otra, en fin, conversar con nuestros colegas sobre investigación, principalmente con aquellos con quienes normalmente no tenemos oportunidad de hacerlo por el vorágine del día a día de nuestro trabajo.

A lo largo de estos seis años hemos conocido el trabajo de muchos de ustedes, y al final de cada Congreso, las evaluaciones siempre han mostrado que, aunque podemos mejorar en la dinámica del Congreso, la organización del programa o la presentación de los pósters, vale la pena mantener este espacio. Es por ello que seguimos organizándolo. Agradecemos la participación y asistencia de todos, así como el entusiasmo, la dedicación, el interés de los investigadores que presentarán

1 Palabras de inauguración del VI Congreso Interdisciplinario de Investigación de la UCA. Auditorio Xabier Gorostiaga, S.J., 17 de mayo de 2012.

Vicerrectora Académica de la UCA. 
sus investigaciones a través de ponencias o de pósters.

El tema inaugural de este VI Congreso trata sobre el desarrollo de la investigación en el Pregrado. Escogimos esta temática porque estamos decididos a fortalecer las competencias investigativas de nuestros estudiantes, compromiso asumido en Pregrado y también en Posgrado.

Hemos creado programas enfocados en el desarrollo de la investigación formativa pues pretendemos facilitar los medios y las condiciones institucionales necesarios para desarrollar competencias investigativas en los estudiantes de la UCA.

Consideramos que "la integración de la investigación en el currículo ofrece un enriquecimiento en la incorporación de la práctica investigativa permanente dentro de los procesos de aprendizaje. Lo anterior supone una clara integración entre la teoría y la práctica, a la vez que una profunda articulación entre el desarrollo del currículo y la investigación. Por lo tanto, la enseñanza debe realizarse a través de la creación de oportunidades de aprendizaje, orientación y ayuda por parte del docente, para la adquisición de habilidades y destrezas investigativas" (Programa de Investigación Formativa para el Pregrado, p. 1).

Este programa también considera la investigación como una poderosa herramienta del proceso de enseñanza-aprendizaje, porque permite que los estudiantes hagan preguntas interesantes y aprendan a seguir una ruta adecuada para responderlas. Nuestros estudiantes aprenden a través de la identificación de preguntas relevantes, la revisión exhaustiva de los estudios anteriores sobre el tema (subir a hombros de gigantes como decía Newton), la definición de categorías de análisis, la escogencia de los métodos científicamente más adecuados para responder a la pregunta formulada y el análisis en profundidad de los resultados obtenidos para formular conclusiones sustentadas. Nuestros estudiantes aprenden porque desarrollan capacidades intelectuales de orden superior pues el proceso investigativo supone análisis, síntesis, conceptualización para abstraer los rasgos que son necesarios para describir una situación o un problema, manejo de información para buscar y seleccionar la información necesaria, pensamiento crítico para proponer hipótesis y evaluar la consistencia de las propias ideas, de lo que se lee, de lo que se escucha, de lo que se observa, formular teorías y modelos alternativos.

Todas estas capacidades se desarrollan de manera progresiva, es por ello que no es responsabilidad de un profesor o de una asignatura desarrollar las competencias investigativas en los estudiantes de cada carrera. Es responsabilidad de varios, de muchos de nosotros, y es por ello que debemos articular una serie de estrategias que puedan incidir de manera positiva en la formación de esta competencia.

Hoy invitamos a Susan Jackels, profesora de la Universidad de Seattle, para compartir con nosotros su enorme experiencia sobre el tema y algunas ideas y estrategias para que podamos, como universidad, fortalecer las competencias investigativas de nuestros estudiantes y por qué no decir, fortalecer nuestras competencias investigativas también. Quiero agradecer a la Dra. Jackels su disposición y generosidad.

Aprovecho para agradecer al equipo de la Dirección de Investigación que desde el inicio del año ha puesto las condiciones para hacer posible este congreso, a los académicos que colaboraron en la selección de las ponencias y a los ponentes, muchas gracias por compartir lo que hacen. El desarrollo de la ciencia se da porque 
Encuentro No. 92, 106-108, 2012

hay generosidad para compartir, hay humildad para reconocer las limitaciones de nuestros hallazgos y hay mentes acuciosas que hacen preguntas interesantes y apuntan a problemáticas relevantes que nos llaman a buscar respuestas.

Quiero finalizar afirmando que estamos haciendo esfuerzos a nivel institucional para fortalecer la investigación en la Universidad, para promover espacios de formación y actualización sobre investigación, para incentivar a que la investigación sea parte del quehacer de todos nosotros académicos. Sin embargo, todos estos esfuerzos sólo se transforman en resultados concretos con la participación, la colaboración y los aportes de todos y todas. 